\title{
Relationship between environmental exposure to pesticides and anthropometric outcomes of boys in the rural Western Cape, South Africa
}

\author{
A A Ochieng, ${ }^{1} \mathrm{MPH} ; \mathrm{M}$ A Dalvie, ${ }^{1} \mathrm{PhD} ; \mathrm{F}$ Little, ${ }^{2} \mathrm{PhD} ; \mathrm{H}$ Kromhout, ${ }^{3} \mathrm{PhD}$ \\ ${ }^{1}$ Centre for Occupational and Environmental Health Research, School of Public Health and Family Medicine, Faculty of Health Sciences, \\ University of Cape Town, South Africa \\ ${ }^{2}$ Department of Statistical Sciences, University of Cape Town, South Africa \\ ${ }^{3}$ Division of Environmental Epidemiology, Institute for Risk Assessment Sciences, Utrecht University, the Netherlands
}

Corresponding author: $M$ A Dalvie (aqiel.dalvie@uct.ac.za)

Background. Rural residents in the Western Cape (WC), South Africa (SA) are highly exposed to agricultural pesticides that could impact their reproductive development. However, epidemiological evidence of the effect of pesticides on pubertal growth is contradictory.

Objective. To investigate the effect of pesticide exposure measured using indices of environmental exposure to pesticides on the pubertal growth of boys in rural WC, SA.

Methods. A cross-sectional study of 269 boys (177 of whom gave a history of residing on farms) was conducted. A questionnaire was administered, height and weight were measured and body mass index was calculated. A proximity index (PI) and spraying index (SI) was developed, measuring the lifetime average home distance from pesticide spraying and average frequency of spraying pesticides on a farm, respectively.

Results. Median age of boys was 12.4 years (interquartile range 9.5 - 13.3). More than $60 \%$ boys had height and weight $<50$ th percentile for age. After adjusting for confounders, PI was significantly associated with shorter stature and lower weight $(-1.7 \mathrm{~cm} / 10$-fold decrease, $p=0.02$ and $-1.24 \mathrm{~kg} / 10$-fold decrease, $p=0.04$; respectively $)$ and SI was non-significantly associated $(-1.4 \mathrm{~cm} / 10$-fold increase, $p=0.05$ and $-1.1 \mathrm{~cm} / 10$-fold increase, $p=0.06$; respectively). Associations were stronger for boys aged $<11$ years and were weaker when excluding nonfarm boys. There were no other associations between outcome and exposure.

Conclusions. The use of quantitative exposure indices showed that lower heights and weights might be associated with pesticide exposure in farm boys v. non-farm boys, but not among farm boys. Lower anthropometric measurements among farm boys v. non-farm boys appear stronger at a younger age. The indices of environmental exposure to pesticides require further development.

S Afr Med J 2013;103(12):942-947. DOI:10.7196/SAMJ.6942

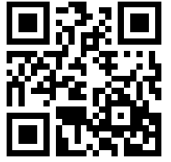

Recent laboratory and epidemiological studies have provided evidence that hormonally active substances can interfere with endocrine signalling pathways, thereby influencing growth and development. ${ }^{[1]}$ Many of the most commonly used contemporary pesticides in South African (SA) agriculture such as prochloraz, glyphosate, endosulphan, chlorpyrifos, iprodione, fenarimol and fenvalerate are hormonally active and have also been shown to cause adverse developmental effects in laboratory animals or in humans. ${ }^{[2]}$

A previous study in the Western Cape (WC), SA, where crop farming is important, has shown that pesticides such as endosulphan, chlorpyrifos, iprodione and fenvalerate are present in the environment, including drinking water sources. ${ }^{[3]}$ Dialkyl phosphate (a metabolite of organophosphate pesticides) and endosulphan levels (median $1587 \mu \mathrm{g} / \mathrm{g}$ creatinine and $366 \mathrm{mg} / \mathrm{l}$, respectively) measured in WC farm workers were higher than those measured in non-farm residents of other countries and in farm workers of most other countries ${ }^{[4,5]}$ Rural residents in the WC are therefore highly exposed to agricultural pesticides that could impact their reproductive development.

Epidemiological evidence on the effect of pesticides on pubertal growth is contradictory and has exclusively focused on environmental exposure of dichlorodiphenyltrichloroethane (DDT). A prospective study conducted ${ }^{[6]}$ on adolescent males in
Philadelphia, USA, born during the period after DDT spraying had been stopped, showed that those with higher prenatal exposure to $\mathrm{p}, \mathrm{p}^{\prime}$-dichlorodiphenyldichloroethylene ( $\left.\mathrm{p}, \mathrm{p}^{\prime}-\mathrm{DDE}\right)$ had increased height and body mass index (BMI) than those with lower exposures. However, when the study was repeated 4 years later on boys born during the period when DDT was used, no associations were found between p,p'-DDE and anthropometric measurements. ${ }^{[7]}$ On the other hand, a prospective study conducted in Germany ${ }^{[8]}$ showed no effect on the height of boys, although reduced height among girls was associated with exposure to higher postnatal childhood p,p'-DDE concentrations. Also, a prospective cohort study done in the USA revealed significantly reduced height among boys between ages 4 and 7 years in the high-exposure group. ${ }^{[9]}$ A recent Russian cohort study of 499 boys aged 8 - 9 years revealed lower mean BMI and height $Z$-scores associated with p,p'-DDE. ${ }^{[10]}$ This contradictory epidemiological evidence in the literature of the effects of pesticides on pubertal development of boys requires further investigation.

Careful characterisation of exposure to pesticides in the agricultural setting is an enormous challenge. Environmental and biological monitoring data are largely unavailable. Farm residents, including women and children, are exposed to pesticides through drinking water and recreational water, food, pesticide drift in homes and schools and contact with contaminated surfaces. ${ }^{[4]}$ 
This study was part of an earlier study conducted by English et al ${ }^{[2]}$ showing that boys living on farms in the rural WC had shorter stature and weight than boys who did not reside on farms.

\section{Objective}

To investigate the relationship between growth and pesticide exposure using various quantitative indices of environmental pesticide exposure instead of the dichotomous exposure index used in the earlier study. Additionally, the effect of pesticides on growth in different age groups was investigated.

\section{Methods}

The study methods are described in detail elsewhere ${ }^{[3]}$ and a summary of the methods are provided. The hypothesis of the study was that hormonally active agricultural pesticides impact pubertal growth due to an alteration of growth hormone release by the pituitary gland.

Institutional Review Board approval for the study was granted by the Ethics Review Board of the University of Cape Town (ref. no. 279/2005). The parent or guardian of each boy signed a consent form before they participated in the study.

\section{Population and study design}

A cross-sectional study of 269 boys aged 5 - 19 years from the rural WC was conducted from April 2007 to March 2008. Boys were recruited from 8 primary and secondary schools in three agriculturally intense areas (Hex River Valley, Grabouw, Piketberg) with established pesticide contamination. ${ }^{[3]}$ The study sample was stratified by age group corresponding to pubertal stages for unexposed boys as follows: 5 - 9 years (pre-pubertal); 9.1 - 11 years (early puberty); 11.1 - 14 years (mid-late puberty) and $>14$ years (post-puberty).

\section{Questionnaire and physical examination}

Trained interviewers administered questionnaires to parents or guardians in Afrikaans, the language of preference. The questionnaire included sections on demography, general medical history, genital health history, mothers' personal habits during pregnancy, and lifetime environmental exposure to agricultural pesticides, domestic pesticide use, phyto-oestrogen intake and lifestyle factors. Questions were based on previous local studies in similar populations. ${ }^{[1]}$ The section on lifetime environmental exposure to agricultural pesticides elicited information on all the places the participant had resided since birth. The use of mobile technology (Mobile Researcher, Clyral) was implemented in the administration and capture of questionnaire data.

A trained male nurse, who was blinded as to whether the boys lived on a farm or not, recorded height and weight (using a calibrated scale) according to standardised methods and calculated the BMI. ${ }^{[12]}$

\section{Statistical analysis}

Data were analysed using STATA (version 10.1). Two exposure indices including a proximity index (PI) and a spraying index (SI) were developed from the exposure information collected by questionnaire.

- The PI was calculated as the average distance of home from the spraying area of all places lived using the following equation: PI $(\mathrm{m} /$ year $)=(\mathrm{D} 1 \mathrm{Y} 1+\mathrm{D} 2 \mathrm{Y} 2 \ldots . \mathrm{DxYx}) /$ age $($ in years $)$, where $\mathrm{Di}=$ distance of home from pesticide spraying area $(\mathrm{m}), \mathrm{Yi}=$ years lived at the place of residence. The value of Di for those not living on a farm was determined employing an algorithm in STATA that randomly allocated distances between 500 and $1700 \mathrm{~m}$ (the estimated range in distance that non-farm participants currently live from farming areas) using a uniform distribution.
- The SI was calculated as the lifetime average number of spraying days per year on farms lived using the following equation: SI (days) $\left(B_{1} Y_{1}+B_{2} Y_{2} \ldots+B_{x} Y_{x}\right) /$ age (in years), where $B_{i}=$ total number of days per year sprayed (including boom, tractor and aeroplane spraying) on a farm (days $=0$ if not living on a farm), $\mathrm{Y}_{\mathrm{i}}=$ the number of years lived at the place of residence.

The distributions of the exposure indices were skewed due to some very large values. We transformed all exposure indices by taking $\log _{10}$ to ensure more symmetric distributions and to facilitate interpretation in terms of a multiplicative increase in exposure rather than the less meaningful 1 unit absolute increase in exposure indices. The primary exposure variables therefore were the two exposure indices that were analysed as continuous variables. The primary outcome variables were anthropometric measurements (height, weight, and BMI), which were also continuous.

Univariate and bivariate exploration of the data were performed. Multiple linear regression analysis was used to test for associations between the individual outcomes and exposure while controlling for confounding. Confounders were selected on an a priori basis, according to biological plausibility, or using bivariate testing. Age and household income (marker of socioeconomic status) were selected a priori for all outcomes. No other confounders were selected from bivariate testing. Further analysis was conducted seeking to investigate exposure outcome relationships per age category. Sensitivity analyses were conducted, including parental education (highest grade completed) and an indicator variable for chronic disease in multivariate models.

\section{Results}

Detailed univariate results by farm/non-farm residence have been published previously. ${ }^{[2]}$ Boys were classified as farm boys $(n=177)$ or non-farm boys $(n=92)$ based on their lifetime residential history.

\section{Participation}

A total of 269 participants were recruited (overall response rate of selected boys was 98.2\%), 37\% ( $n=100)$ from Grabouw, 34\% $(n=91)$ from Piketberg and 29\% $(n=78)$ from the Hex River Valley. There was good participation by boys in all the age categories (Table 1).

\section{Demographic, socioeconomic status and medical history} The median age of the participants was 12.4 years (interquartile range (IQR) 9.5 - 13.3).

The prevalence of lifetime chronic medical conditions such as diabetes, epilepsy and heart problems was below $2 \%$, while $9.3 \%$ of participants $(n=25)$ had asthma and 5.6\% $(n=15)$ had tuberculosis. One boy was reported to be HIV-positive and two boys had fetal alcohol syndrome. Two boys previously experienced pesticide poisoning. Four boys (1.5\%) had hypospadias and none had cryptorchidism (discussed in English et al. ${ }^{[2]}$ ).

\section{Household pesticides, phyto-oestrogen intake and pre- natal exposures}

More than half of households used pesticides for household purposes. Other household pesticide exposures included household members working with pesticides, bringing contaminated clothing home and the use of empty pesticide containers at home for domestic use.

Phyto-oestrogen intake in the form of lifetime vegetable intake was prevalent among the vast majority of boys (95\%), while intake of nuts and soya was prevalent among about two-thirds of boys. Less than $3 \%$ of boys smoked, consumed alcohol and/or used drugs. 
Table 1. Demographics, household pesticide exposure, phyto-oestrogen intake, mothers' exposures during pregnancy and exposure to agricultural spraying on farms $(N=269)$

\begin{tabular}{|c|c|}
\hline Variable & \\
\hline \multicolumn{2}{|l|}{ Socioeconomic status, $n(\%)$} \\
\hline Sometimes or often goes hungry & $8(3)$ \\
\hline \multicolumn{2}{|l|}{ Household pesticide exposure, $n(\%)$} \\
\hline Use household pesticides & $152(56.5)$ \\
\hline Fumigate house & $15(5.6)$ \\
\hline Household member works with pesticides & $22(8.2)$ \\
\hline Pesticide-contaminated clothing washed at home & $6(2.2)$ \\
\hline Use pesticide containers at home & $6(2.2)$ \\
\hline \multicolumn{2}{|l|}{ Lifetime phyto-oestrogen intake, $n(\%)$} \\
\hline Vegetables & $257(95)$ \\
\hline Nuts & $161(59.9)$ \\
\hline Soya & $194(72.1)$ \\
\hline \multicolumn{2}{|l|}{ Mothers' exposures during pregnancy, $n(\%)$} \\
\hline Sprayed pesticides & $6(2.2)$ \\
\hline Worked in vineyard during pesticide spraying & $78(29)$ \\
\hline Smoked & $114(42.3)$ \\
\hline Consumed alcohol & $45(16.7)$ \\
\hline \multicolumn{2}{|c|}{ Agricultural pesticide exposure in current home among boys living on farm $(N=175), n(\%)$} \\
\hline Pesticides sprayed on farm during current year & $171(97.7)$ \\
\hline Farm spraying drifted into house & $76(44.4)$ \\
\hline \multicolumn{2}{|l|}{ Water source } \\
\hline River/dam & $87(34.4)$ \\
\hline Municipal & $166(66.5)$ \\
\hline Swimming in nearby dams & $77(28.62)$ \\
\hline Walking in vineyards after spraying & $50(28.6)$ \\
\hline Helping on farm & $32(11.5)$ \\
\hline Eating crops from vineyards & $85(31.6)$ \\
\hline Use of empty pesticide containers & $12(04.4)$ \\
\hline Mixing of pesticides & $2(0.7)$ \\
\hline \multicolumn{2}{|l|}{ Lifetime residency, $n(\%)$} \\
\hline Lived in current location throughout life & $223(82.9)$ \\
\hline Ever lived on a farm & $177(65.8)$ \\
\hline Lived only on farm & $94(34.2)$ \\
\hline \multicolumn{2}{|l|}{ Age (years), median (IQR) } \\
\hline $5-9(n=41)$ & $8.7(8.3-8.8)$ \\
\hline$>9-11(n=77)$ & $9.8(9.3-10.5)$ \\
\hline$>11-14(n=119)$ & $12.7(12.1-13.3)$ \\
\hline$>14(n=32)$ & $15(14.5-16.1)$ \\
\hline Birth weight $(\mathrm{kg})(n=205)$, median (IQR) & $2.8(2.5-3.3)$ \\
\hline Household income (US\$), median (IQR) & $250(163-340)$ \\
\hline Distance of current home from spraying on farm (m), median (IQR) & $12.5(0.5-325)$ \\
\hline \multicolumn{2}{|l|}{ Exposure indices, median (IQR) } \\
\hline $\mathrm{PI}(\mathrm{m})^{*}$ & $100(17.5-974.6)$ \\
\hline SI (days/year) ${ }^{\dagger}$ & $36.8(0-82.5)$ \\
\hline
\end{tabular}


Few mothers (2.2\%) reported that they sprayed pesticides during pregnancy but nearly a third $(29.4 \%)$ had worked in the vineyard while spraying activities took place. Nearly half of the mothers smoked and about a fifth consumed alcohol during pregnancy.

\section{Exposure of farm boys to agricultural spraying on farms} Boys living on farms were exposed to agricultural pesticides through a number of routes that included living near to sites of spraying, pesticides drifting into homes, coming into contact with pesticides outside the house while spraying occurs, drinking water from unprotected sources, walking in vineyards after spraying, helping in the fields on farms, swimming in farm dams and nearby rivers that contain pesticide residues, eating crops from vineyards and orchards, and using empty pesticide containers. The majority of boys $(83 \%)$ lived in one location throughout their life, with the rest living in 2 - 5 different locations. About two-thirds of boys (65.8\%) had lived on a farm in their lifetime and $34.2 \%$ had lived only on a farm.

\section{Anthropometric measurements}

The median height of the boys was $137.9 \mathrm{~cm}$ (IQR 129 - 148.1), weight was $33 \mathrm{~kg}$ (IQR 27 - 43) and BMI was $17.5 \mathrm{~kg} / \mathrm{m}^{2}$ (IQR 16 - 19.1). The proportions of boys below the Centers for Disease Control (CDC) 50th height, weight and BMI percentile for age ${ }^{[13]}$ were $71.6 \%(n=192), 66.8 \%$ $(n=179)$ and $39.6 \%(n=106)$, respectively; and those below the CDC 25th height, weight and BMI percentile for age were $57.1 \%(n=153)$, $41.8 \%(n=112)$ and $19.4 \%(n=52)$, respectively. The results were not substantially different when using World Health Organization charts. ${ }^{[14]}$

\section{Adjusted associations between exposure indices and anthropometric outcomes}

Table 2 summarises the results of multiple linear regression analysis investigating the associations between the exposure indices and anthropometric measurements. The results (Table 2) show positive associations between PI and height, as well as weight, when adjusting for confounding (age and household income), showing that boys who had lived near farms where spraying took place were of shorter stature and lower weight. There were negative non-significant associations between SI and height and weight, when adjusting for confounding, showing that boys exposed to more spraying on farms were of shorter stature and lower weight. The regression coefficients predict that for every 10 -fold increase in lifetime distance from the farm a boy's height and weight increased by $1.7 \mathrm{~cm}(p=0.02)$ and $1.2 \mathrm{~kg}$ ( $p=0.04)$, respectively. The model also predicted a $1.4 \mathrm{~cm}$ decrease in height for every 10 -fold increase in days of spraying done on the farm per year $(p=0.05)$. The associations between the exposure indices and BMI were not significant.

These results were consistent with linear regression analysis using a PI whereby the distances of boys not living on farms were assigned an arbitrary distance of $1000 \mathrm{~m}$.

Further analyses investigating exposure outcome relationships among only those with a history of living on a farm as determined in the earlier study ${ }^{[2]}$ and therefore excluding non-farm boys, found no statistically significant association between the exposure indices and outcomes (Table 2). Inclusion of the parental education and an indicator variable for chronic disease into multivariate models had minimal effect on health/outcome relationships.

The association of height and weight with PI and SI was seen in the different age strata (Table 3 ), though was not always statistically significant. The regression coefficients seem to indicate that the associations of PI with height and weight are stronger for boys aged $<11$ years.

The associations between PI and BMI in all the age groups were non-significant. These findings are consistent with logistic regression analysis, whereby the outcomes were dichotomised at the 25th and 50th percentiles.

Further analysis was conducted including the dichotomous exposure variable (farm v. non-farm) used in the earlier study, ${ }^{[2]}$ in the multivariate model to assess the impact on the strength of association of the exposure indices and also of household income as an indicator of socioeconomic status. The results (Table 4) show PI (regression coefficient (95\% confidence interval (CI)) for height and weight, respectively: $-0.08(-2.56-2.39) ;-0.13(-1.93-1.68)$ and SI (regression coefficient, 95\% CI for height and weight respectively: $0.11(-1.81-2.03) ;-0.18(-0.89-0.52)$ disappear as predictors for height and weight $\mathrm{v}$. the results in Table 2, with lifetime residence on a farm a substantially stronger predictor (e.g. regression coefficient, 95\% CI when using PI and outcomes height and weight, respectively: $-4.19(-8.76-0.38) ;-3.91(-7.47--0.35))$. Household income remains a strong socioeconomic predictor for height.

\section{Discussion}

The results in this study show that boys who have resided in closer proximity to agricultural pesticide spraying and/or were exposed to

Table 2. Association between the exposure indexes and outcomes adjusted for age and household income*

\begin{tabular}{|c|c|c|c|c|}
\hline \multirow[b]{2}{*}{ Outcome variables } & \multicolumn{2}{|c|}{ All boys $(N=269)^{+, s}$} & \multicolumn{2}{|c|}{ Farm boys $(N=177)^{ \pm, s}$} \\
\hline & $\begin{array}{l}\text { Regression coefficient } \\
(95 \% \mathrm{CI})\end{array}$ & $p$-value & $\begin{array}{l}\text { Regression coefficient } \\
(95 \% \mathrm{CI})\end{array}$ & $p$-value \\
\hline \multicolumn{5}{|l|}{ PI (log m) } \\
\hline Height $(\mathrm{cm})$ & $1.73(0.23-3.23)$ & 0.02 & $-0.06(-2.44-2.31)$ & 0.96 \\
\hline Weight (kg) & $1.24(0.04-2.45)$ & 0.04 & $0.16(-1.68-1.99)$ & 0.87 \\
\hline BMI $\left(\mathrm{kg} / \mathrm{m}^{2}\right)$ & $0.21(-0.18-0.6)$ & 0.28 & $0.19(-0.42-0.79)$ & 0.54 \\
\hline \multicolumn{5}{|l|}{ SI (log days/year) } \\
\hline Height $(\mathrm{cm})$ & $-1.38(-2.78-0.03)$ & 0.05 & $0.05(-1.68-1.79)$ & 0.95 \\
\hline Weight (cm) & $-1.09(-2.22-0.02)$ & 0.06 & $-0.19(-1.54-1.16)$ & 0.78 \\
\hline BMI $\left(\mathrm{kg} / \mathrm{m}^{2}\right)$ & $-0.16(-0.53-0.19)$ & 0.37 & $-0.06(-0.51-0.38)$ & 0.78 \\
\hline \multicolumn{5}{|c|}{$\begin{array}{l}\mathrm{CI}=\text { confidence interval; } \mathrm{PI}=\text { proximity index; } \mathrm{BMI}=\text { body mass index; } \mathrm{SI} \text { = spraying index. } \\
\text { *Using multiple linear regression analysis. } \\
\text { 'Including all the boys (farm and non-farm boys) in the study. } \\
\text { 'Including only boys who were classified as farm boys. } \\
\text { 'Results based on boy' residential history. }\end{array}$} \\
\hline
\end{tabular}


Table 3. Relationship between exposure indices and outcomes in the different age groups adjusted for age and household income ${ }^{\star}$

\begin{tabular}{|c|c|c|c|c|c|c|}
\hline \multirow[b]{2}{*}{ Age group } & \multicolumn{2}{|c|}{ Height $(\mathrm{cm})$} & \multicolumn{2}{|c|}{ Weight (kg) } & \multicolumn{2}{|l|}{ BMI $\left(\mathbf{k g} / \mathbf{m}^{2}\right)$} \\
\hline & $\begin{array}{l}\text { Regression coefficient } \\
(95 \% \mathrm{CI})\end{array}$ & $p$-value & $\begin{array}{l}\text { Regression coefficient } \\
(95 \% \text { CI })\end{array}$ & $p$-value & $\begin{array}{l}\text { Regression coefficient } \\
(95 \% \mathrm{CI})\end{array}$ & $p$-value \\
\hline \multicolumn{7}{|l|}{5 - 9 years $(n=41)$} \\
\hline PI $(\log \mathrm{m})$ & $3.66(0.47-6.8)$ & 0.03 & $1.84(0.42-3.25)$ & 0.01 & $0.33(-0.49-1.14)$ & 0.42 \\
\hline SI (log days/year) & $-0.87(-3.89-2.14)$ & 0.56 & $-0.41(-1.77-0.95)$ & 0.55 & $-0.05(-0.78-0.68)$ & 0.88 \\
\hline \multicolumn{7}{|l|}{$>9-11$ years $(n=77)$} \\
\hline PI $(\log \mathrm{m})$ & $2.44(0.44-4.44)$ & 0.02 & $1.76(0.05-3.47)$ & 0.04 & $0.44(-0.29-1.19)$ & 0.24 \\
\hline SI (log days/year) & $-0.16(-1.87-1.56)$ & 0.86 & $-0.47(-1.92-0.97)$ & 0.52 & $-0.17(-0.79-0.45)$ & 0.59 \\
\hline \multicolumn{7}{|l|}{$>11-14$ years $(n=119)$} \\
\hline PI $(\log \mathrm{m})$ & $0.54(-1.89-2.97)$ & 0.66 & $0.47(-1.66-2.61)$ & 0.66 & $-0.04(-0.71-0.62)$ & 0.89 \\
\hline SI (log days/year) & $-2.37(-4.72--0.03)$ & 0.05 & $-1.35(-3.43-0.73)$ & 0.20 & $0.04(-0.62-0.69)$ & 0.92 \\
\hline \multicolumn{7}{|l|}{$>14$ years $(n=32)$} \\
\hline PI $(\log \mathrm{m})$ & $1.70(-3.59-6.99)$ & 0.52 & $0.95(-3.66-5.55)$ & 0.68 & $0.11(-1.13-1.35)$ & 0.86 \\
\hline SI (log days/year) & $1.20(-3.99-6.39)$ & 0.64 & $-0.38(-4.89-4.13)$ & 0.86 & $0.55(-1.74-0.65)$ & 0.36 \\
\hline
\end{tabular}

more frequent agricultural pesticide spraying throughout their life are shorter and weigh less than boys who have not. However, when boys who do not have a history of living on farms are excluded from the analysis the association disappears. This suggests that 'farm residence' (which assumes that farm boys are located closer to, and are exposed to higher intensities of, spraying than non-farm boys) is the determining factor for the association and that proximity to, and intensity of spraying, among farm boys is not the driving factor for the association. When lifetime residence on a farm is included in the statistical models (Table 4), it is a stronger predictor of height and weight than the exposure indices as indicated by the lower $p$-values of the regression coefficients, thus providing further indications that farm residence is the factor determining environmental exposure. Household income remains a strong socioeconomic predictor in these models as it is either statistically significant, or near to significance, suggesting that the association with farm residence is not due to socioeconomic differences. However, it is possible that lifetime residence on a farm could to some extent act as a second socioeconomic variable, controlling for differences between 'farm boys' and 'non-farm' boys not accounted by household income. Although PI and SI merely reflected farm residence, they did provide greater clarity for the association with height and weight; the association among farm boys could only be explored and the impact of socioeconomic status requires investigation in greater detail.

Height and weight measurements as well as birth weights (Table 1) indicate that the boys

Table 4. Association between the PI and SI and height adjusting for age, household income and lifetime residence on a farm $(N=269)^{x,+}$

\begin{tabular}{|c|c|c|}
\hline Predictors & Regression coefficient $(95 \% \mathrm{CI})$ & $p$-value \\
\hline \multicolumn{3}{|l|}{ Height (cm) } \\
\hline PI $(\log m)$ & $-0.08(-2.56-2.39)$ & 0.95 \\
\hline Farm boy $(\text { Yes, No) })^{\ddagger}$ & $-4.19(-8.76-0.38)$ & 0.07 \\
\hline Age (years) & $4.26(3.69-4.82)$ & $<0.001$ \\
\hline Household income (US\$) & $2.13(-0.23-4.49)$ & 0.08 \\
\hline SI (log days/year) & $-0.13(-1.93-1.68)$ & 0.89 \\
\hline Farm boy $(\text { Yes, No })^{\ddagger}$ & $-3.91(-7.47--0.35)$ & 0.03 \\
\hline Age (years) & $4.26(3.69-4.82)$ & $<0.001$ \\
\hline Household income (US\$) & $2.14(-0.23-4.51)$ & 0.08 \\
\hline \multicolumn{3}{|l|}{ Weight (kg) } \\
\hline PI $(\log m)$ & $0.11(-1.81-2.03)$ & 0.91 \\
\hline Farm boy $(\text { Yes, No) })^{\ddagger}$ & $-1.41(-5-2.17)$ & 0.44 \\
\hline Age (years) & $3.39(2.95-3.83)$ & $<0.001$ \\
\hline Household income (US\$) & $0.001(0.001-0.002)$ & $<0.001$ \\
\hline SI (log days/year) & $-0.18(-0.89-0.52)$ & 0.61 \\
\hline Farm boy $(\text { Yes, No })^{\ddagger}$ & $-1.07(-4.04-1.90)$ & 0.48 \\
\hline Age (years) & $3.40(2.96-3.83)$ & $<0.001$ \\
\hline Household income (US\$) & $0.001(0.001-0.002)$ & $<0.001$ \\
\hline \multicolumn{3}{|c|}{$\begin{array}{l}\text { PI = proximity index; SI = spraying index; } \mathrm{CI} \text { = confidence interval. } \\
\text { *USing multiple linear regression analysis. } \\
\text { "boys were classified as farm boys or non-farm boys based on their lifetime residential history. } \\
\text { "Variable indicating whether boys lived on a farm throughout their lives or not. }\end{array}$} \\
\hline
\end{tabular}

have markedly lower in utero and childhood growth than growth standards, ${ }^{[13]}$ most likely reflecting low socioeconomic status and consequent poor nutrition. Nutritional status could have accounted for anthropometric measurements of participating boys in the study. The lack of dietary intake data as a potential confounder in this study is therefore a limitation. However, farm and non-farm boys were recruited from neighbouring areas, which should ensure that their dietary intake was not substantially different. Household income, as an indicator of socioeconomic status and a strong determinant of nutritional status, was 
also not substantially different in the two groups; it was low in both groups and it was also included as a confounder in the analysis. ${ }^{[15]}$

The use of PI and SI, particularly among farm boys, for determining the association between pesticide exposure and height and weight, require further development. Previous studies conducted in the USA, have provided evidence that organophosphate levels in urine and house dust increase with proximity to the nearest spraying area on farms within $300 \mathrm{~m} \cdot{ }^{[16,17]}$ In our study, the respondents' estimation of proximity for those living on farms, especially for past homes, might have been imprecise. Direct measurement through farm visits, not possible in this study due to a lack of funding, could have improved the estimation of proximity to agricultural spraying for homes located on farms. Furthermore, the estimation of proximity to farms for homes not located on farms could be improved through the use of maps or GPS data instead of assigning arbitrary distances. It should be noted, however, that the amount of pesticide drift in homes is influenced by the application methods, meteorological conditions, topography, characteristics of the crop and decisions made by applicators. ${ }^{[18]}$ These factors, as well as the identity and chemical characteristics of the pesticides applied, direct pesticide exposures of participants and intake of pesticides from other routes, are uncertainties when using indices based on distance and the number of spraying days on the farm.

SI was probably also affected by reliance on the respondents' estimation of the number of spraying days on farms and can be improved by contacting the farm management and studying spraying records.

The age-group analysis revealed that the association between PI and height and weight was the strongest for boys aged $<11$ years (Table 3). This could simply be due to the fact that the effect manifests the strongest at age $<11$ years or due to more pesticides absorbed as a result of the larger body surface area to volume ratio of younger boys as well as their slower metabolism of toxicants. ${ }^{[1]}$

The lower height and weight measurements associated with agricultural pesticide spraying are consistent with our hypothesis, that an alteration of growth hormone release by the pituitary gland due to exposure to hormonally active pesticides could have impacted on pubertal growth. Altered levels of reproductive hormones among farm boys $v$. non-farm boys found in the earlier study are further support of our hypothesis. ${ }^{[2]}$ No studies investigating the effect of currently registered agricultural pesticides on pubertal growth were found in the literature, but there is laboratory and epidemiological evidence of reduced height measurements among DDT-exposed boys, although results are contradictory, as discussed earlier. ${ }^{[6-10]}$

\section{Study limitations}

Intake of phyto-oestrogens, which are endocrine disruptors, or the use of endocrine-disrupting pesticides at home, could have confounded the results. Most participating boys were exposed to these substances and the bivariate association with health outcomes was not strong enough for inclusion in multivariate modelling. A key limitation in this study was the cross-sectional design, which precluded us from establishing with certainty whether the associations are the result of a temporal relationship between pesticide exposure and outcomes. Another limitation is the absence of pesticide exposure biomarker data to prove whether pesticide levels were higher among non-farm boys. However, previous studies have shown that non-farm pesticide exposures are substantially lower than pesticide exposures on farms ${ }^{[4,6]}$ and the results of this cross-sectional study could be explored further in a longitudinal study. Although there are limitations in using PI and SI, as discussed earlier, they could be improved for future studies. Exposure misclassification due to non-farm boys' exposure to contaminated water and food or pesticide drift is possible. However, these exposures are likely to be far less prevalent in non-farm groups. Recall bias due the respondents' memory of boys' childhoods and of mothers' pregnancies is a factor, especially when the parent was not available (as in $23 \%$ of participants). Furthermore, measurement bias may have been introduced during the physical examination of the boys despite training of research staff and other quality control measures aimed at reducing these biases. Although the classification of boys into age categories was based on pubertal stages of unexposed boys, this would have minimal effect on the results of the study as the age range of the participants was sufficiently wide.

\section{Conclusions}

The use of quantitative exposure indices showed that lower heights and weights might be associated with pesticide exposure in farm boys v. non-farm boys, but not among farm boys. Lower anthropometric measurements among farm boys $\mathrm{v}$. non-farm boys appear stronger at a younger age. The reduced anthropometric measurements of pubertal farm boys may be due to environmental exposure to hormonally active agricultural pesticides. The indices of environmental exposure to pesticides require further development.

A prospective and larger cohort study of boys in different age categories is needed, as are more detailed exposure data including annual bio-monitoring data. Further analysis of pesticide bio-monitoring data is currently underway. We recommend initiatives to change knowledge, attitudes and practices through the education of farmers, farm workers and other rural residents about the harmful effects of pesticides.

Acknowledgements. The SA National Research Foundation, SA Medical Research Council and University of Cape Town Research Committee are acknowledged for their grant support. Mr Algernon Africa is acknowledged for his assistance in the study.

\section{References}

1. Newbold RR, Padilla-Banks E, Jefferson WN, Heindel JJ. Effects of endocrine disruptors on obesity. Int J Androl 2008;31(2):201-208. [http://dx.doi.org/10.1111/j.1365-2605.2007.00858.x]

English RG, Perry M, Lee MM, Hoffman E, Delport S, Dalvie MA. Farm residence and reproductive health among boys in rural South Africa. Environ Int 2012;47:73-79. [http://dx.doi.org/10.1016/jenvint.2012.06.006] Dalvie MA, Cairncross E Solomon A. London L Contamination of rural surface and ground water by endosulfan in farming areas of the Western Cape, South Africa. Environ Health 2003;2(1):1. [http:// endosulfan in farming areas of the

4. Dalvie MA, Africa A, Solomons A, London L, Brouwer D, Kromhout $\mathrm{H}$. Pesticide exposure and blood endosulfan levels after first season spray amongst farm workers in the Western Cape, South Africa. I Endosulfan levels after first season spray amongst farm workers in the Western Cape, Sou

Environ Sci Health B 2009;44(3):271-277. [http://dx.doi.org/10.1080/03601230902728351] 5. Dalvie MA, Naik I, Channa K, London L. Urinary dialkyl phosphate levels before and after first season
chlorpyrifos spraying amongst farm workers in the Western Cape, South Africa. J Environ Sci Health B 2011;46(2):163-172. [http://dx.doi.org/10.1080/03601234.2011.535384]

6. Gladen BC, Ragan NB, Rogan WJ. Pubertal growth and development and prenatal and lactational exposure to polychlorinated biphenyls and dichlorodiphenyl dichloroethene. J Pediatr 2000;136(4):490-496. [http://dx.doi.org/10.1016/S0022-3476(00)90012-X]

7 Gladen BC, Klebanoff MA, Hediger ML, et al. Prenatal DDT exposure in relation to anthropometric and pubertal measures in adolescent males. Environ Health Perspect 2004;112(17):1761-1767. [http:// dx.doi.org/10.1289/ehp.7287]

8. Karmaus W, Asakevich S, Indurkhya A, Witten J, Kruse H. Childhood growth and exposure to dichlorodiphenyl dichloroethene and polychlorinated biphenyls. J Pediatr 2002;140(1):33-39. [http:// dx.doi.org/10.1067/mpd.2002.120764]

9. Ribas-Fitó N, Gladen BC, Brock JW, Klebanoff MA, Longnecker MP. Prenatal exposure to 1,1-dichloro-2,2-bis (p-chlorophenyl)ethylene (p,p'-DDE) in relation to child growth. Int J Epidemiol 1,1-dichloro-2,2-bis (p-chlorophenyl)ethylene (p,p-DDE)

10. Burns JS, Williams PL, Sergeyev O, et al. Serum concentrations of organochlorine pesticides and growth among Russian boys. Environ Health Perspect 2011;120:303-308. [http://dx.doi.org/10.1289/ehp.1103743] 11. Dalvie MA, Myers JE, Thompson ML, Robins TG, Dyer S. The hormonal effects of long term DDT exposure on malaria vector control workers in Limpopo Province, South Africa. Environ Res 2004;96(1):9-19. [http://dx.doi.org/10.1016/j.envres.2003.09.003]

12. CDC. National Health and Nutrition Examination Survey (NHANES). Anthropometry Procedures Manual. http://www.cdc.gov/nchs/data/nhanes/nhanes_07_08/manual_an.pdf (accessed 22 October 2013).

13. CDC. Growth Charts. http://www.cdc.gov/growthcharts/cdc_charts.htm. (accessed 22 October 2013).

14. WHO. The WHO Child Growth Standards. http://www.who.int/childgrowth/standards/en/ (accessed 22 October 2013).

15. Marmot M. The Status Syndrome: How Social Standing Affects Our Health and Longevity. New York: Owl Books, 2004.

16. Coronado GD, Holte S, Vigoren E, Griffith WC, Barr DB. Organophosphate pesticide exposure and residential proximity to nearby fields: Evidence for the drift pathway. I Occup Environ Med 2011:53(8):884-891. [http://dx.doi.org/10.1097/JOM.0b013e318222f03a]

17. Lu C, Fenske RA, Simcox NJ, Kalman D. Pesticide exposure of children in an agricultural community; Evidence of household proximity to farmland and take home exposure pathways. Environ Res 2000;84(3):290-302. [http://dx.doi.org/10.1006/enrs.2000.4076]

18. McCauley LA, Lasarev MR, Higgins G, et al. Work characteristics and pesticide exposures among migrant agricultural families: A community-based research approach. Environ Health Perspect 2001;109(5):533-538. [http://dx.doi.org/10.1289/ehp.01109533]

Accepted 25 September 2013. 